\title{
O Risco na Sociedade ConTEMPorânea ${ }^{(*)}$
}

Raffaele De Giorgi ${ }^{(\star \star)}$

\section{RESUMO}

O trabalho trata do risco como um paradoxo que constitui a modernidade da sociedade contemporânea, apresentado como um dado, uma informação objetiva, e que está vinculado a decisões e ações futuras. O presente artigo apresenta também o conceito de segurança, certeza assumida como racional e alternativa ao risco.

\section{Palavras-chave}

Direito à Saúde; Liberdades Individuais; Risco.

\section{ABSTRACT}

This work approaches the concept of risk as a paradox which composes the modernity of the contemporaneous society. The risk is presented as a objective information and its related to future decisions and actions. This paper also presents the concept of safety, alternative to the risk.

\section{Keywords}

Individual liberty; Right to Health; Risk.

(*) Artigo elaborado a partir de apresentação sobre o tema durante o VII Seminário Internacional de Direito Sanitário, realizado na Faculdade de Saúde Pública da Universidade de São Paulo. São Paulo, 13 a 15 de setembro de 2006.

$\left.{ }^{(* *}\right)$ Professor titular de Teoria Geral do Direito e Sociologia do Direito da Universidade de Lecce, Itália, Diretor do "Centro di Studi Sul Rischio" da Universidade de Lecce. E-mail:<raffaeledegiorgi@gmail.com>. Recebido em 5.1.07. Aprovado em 7.2.07. 


\section{INTRODUÇÃO}

O dramaturgo inglês Harold Pinter dedicou sua obra, sua paixão poética e a força penetrante de suas comédias à representação do drama da guerra, dos massacres e dos sofrimentos inerentes ao mundo do império. $O$ império aparece como o mundo da democracia e da liberdade civil, dos direitos humanos e das intervenções de paz. O escritor foi agraciado com o Prêmio Nobel porque "em suas comédias, revela o abismo que existe sob conversas cotidianas e nos incita a entrar nos cômodos fechados da opressão". O que pode ser visto nesses cômodos e o que se esconde naquele abismo? Nossa resposta é: justiça, paz, segurança, saúde, bem-estar, princípios universais e verdade. Em outras palavras: saber sobre a sociedade e saber sobre o mundo. Mais: ordem, certeza e progresso. Sustentamos que, naqueles cômodos fechados, são elaboradas as percepções do risco na sociedade contemporânea, as técnicas para seu tratamento e as estratégias de segurança. É lá onde se planifica a saúde e se entrelaçam as redes que devem conter aquilo que, pessimamente, convencionou-se chamar de global risk. E o abismo? O abismo é obscuridade, impenetrabilidade e ocultamento. Ele oculta o paradoxo do risco e encobre a própria construção paradoxal. Torna inobservável o observador e inacessível sua observação a outros observadores. Esse bloqueio da observação da observação, o ocaso do observador, possibilita a apresentação do risco como um objeto, como alguma coisa, um estado, uma condição ou, talvez, uma entidade com características de objeto, vale dizer, alguma coisa provida de objetividade. E o objeto é sempre objeto do saber, objeto do conhecimento. Mas, na escuridão do abismo, ainda há lugar para outra coisa: os objetos, na realidade, são autovalores da indicação. Eles se estabilizam através da recursividade da indicação. Aquilo denominado objetividade é justamente essa recursividade, ou seja, a exclusão de outros valores, a invisibilidade da distinção que torna possível a indicação. Mas, a invisibilidade da distinção subtrai da observação a outra parte da distinção, expondo-a ao não-saber, ocultando-a. Assim, a outra parte da distinção é incluída unicamente como risco, como o terceiro incluído que é excluído. A indicação do risco como objeto delimita o saber sobre os acontecimentos e produz risco, pois confia, ao não-saber, as demais distinções possíveis.

Ocorre, assim, algo de grotesco no abismo: o risco do saber é produzido e o risco do risco do não-saber é ocultado. Os eventos são tratados em razão das conexões causais e a circularidade é ativada. Desse modo, inventam-se técnicas de segurança; risco e perigo são produzidos conforme o observador e o destinatário; constrói-se uma gritaria ecológica do saber; fica-se imune à realidade do risco (que é a realidade do não-saber); formam-se os experts em risco e se oculta o risco dos experts. Na medicina, é o "consenso informado": assume-se responsabilidades por eventuais erros dos outros em situações em que se deve escolher sem alternativas de escolha. Ou ainda, o 
"direito à saúde", em que se dispõe, nos espaços entre economia e política, de indivíduos aos quais se pode sempre imputar as conseqüências da privação do acesso à saúde como risco que os próprios indivíduos poderiam evitar.

É mesmo um abismo que existe sob as conversas cotidianas. Sustentamos que outros caminhos reflexivos sejam possíveis e necessários, justificados pelos riscos produzidos pelo saber do risco. Nas considerações a seguir, trataremos o risco como um paradoxo constitutivo da modernidade da sociedade moderna, como um vínculo com o futuro que possibilita o agir em condições de desconhecimento em que são feitas escolhas no presente. $\mathrm{Na}$ simultaneidade e na falta de transparência do acontecer que caracteriza a sociedade contemporânea e que constitui seu presente, deve-se fazer alguma coisa, como, por exemplo, escolher sem saber exatamente como fazê-lo.

\section{CONSTRUÇÃO DO RISCO}

Grande parte da literatura e do senso comum consideram risco uma espécie de realidade subterrânea, uma segunda realidade que transcorre oculta sob a realidade produzida pelo agir, quer o agir singular, quer o dos sistemas sociais. Risco é um tipo de realidade da ameaça ou um tipo de ameaça da realidade conservada silenciosamente. Se não existisse essa ameaça, a ordem continuaria a subsistir. A realidade transcorreria normalmente. Os eventos, o agir, seriam coordenados segundo as expectativas, regulados segundo as previsões e os programas. Em outras palavras: aquilo que se procura realizar poderia ser realizado de modo, digamos, racional. $O$ risco, se verificado, rompe tal ordem. Rompe as conexões entre seus elementos e a continuidade temporal que os mantém agrupados. O risco estabeleceria diferenças entre passado e futuro. Essas diferenças seriam superadas pela capacidade racional de representar o futuro e agir casualmente para sua realização. O estado de conservação dessas condições do agir chama-se segurança. Como a segurança é condição merecedora de preferência, deve-se atribuir a ela um valor positivo. Ao risco, ao contrário, é conferido um valor negativo. E assim a razão é sublimada pela moral. O risco existe e deve ser evitado, minimizado, tratado por meio de medidas de segurança. Os ingrediente do tratamento, as terapias preventivas e as medidas de segurança são infinitas, mesmo se o esquema sobre os quais estão baseados é recorrente e elementar como a racionalidade que o sustenta. É, em outras palavras, bárbaro como a pretensão de universalidade da razão, que pode ser cega, violenta, justamente porque sua racionalidade justifica cegueira e violência. Se percebido o risco de transgressão da ordem do mundo, deve-se intervir para prevenir que isso aconteça. Se uma nova tecnologia for desenvolvida, deve-se controlar seu risco. Se existe o risco de con- 
sumo de drogas entre os jovens, será necessário impor-lhes uma educação rígida que os obrigue a adotar valores úteis e sociais. Se existem riscos para a saúde, deve-se adotar outros estilos de vida. Se o custo da vigilância sanitária for alto, deve-se privatizá-la, pois os serviços privados são mais eficientes, produzem lucros que podem ser investidos para melhorar as condições de saúde de todos. Se a Europa corre o risco de ser tomada pela onda migratória gerida pelas máfias, trancaremos os imigrantes dentro de campos de concentração modernos e, depois, os reenviaremos para casa. Se a Floresta Amazônica queimar, deveremos desenvolver uma consciência ecológica. E, por fim, se a atmosfera é tão poluída que causa danos irreverssíveis à saúde, fixemos índices de poluição que não podem ser ultrapassados. Enquanto não forem ultrapassados, tudo correrá normalmente.

Vamos nos ater a esse ponto. A construção do esquema do risco ou da segurança apresenta sempre as mesmas características. Identifica-se uma situação, uma condição ou uma questão arriscada, ou seja, portadora de um dano atual ou futuro que deveria ser evitado. Ao se dar conta do dano, atribuiIhe a qualificação de risco. O risco é apresentado como um dado, algo dotado de objetividade e que, portanto, é acessível à consciência. O saber impõe sua prevenção, seu tratamento ou bloqueia sua realização e, caso seja atual, impede a continuação de sua permanência. O horizonte longínquo que avalia o nível do risco é a segurança, uma condição artificial de estabilidade e de certeza assumida como racional. Em suma, a alternativa ao risco é a segurança.

Trata-se, entretanto, de uma construção altamente implausível e arriscada (isso é seguro!). O risco não é algo real, não é um dado. É a possibilidade de um evento danoso que uma outra decisão poderia ter evitado. Antes de se saber que o contágio da AIDS ocorre por via sexual, as relações sexuais não eram consideradas relações de risco ou, como uma vez afirmou Luhmann, antes da invenção do guarda-chuva, não existia o risco de se molhar quando chovia. No mesmo sentido, antes da invenção da penicelina não existia o risco de morte por pneumonia, assim como depois da invenção do antibiótico há o risco de se sofrer um choque anafilático, caso se seja alérgico ao medicamento que o médico poderia não ter receitado. E mais: o "consenso informado" sobre os danos provocados por um exame invasivo necessário para a formação do diagnóstico não informa os riscos que eu corro. Não se trata de risco, pois não tenho possibilidades de escolha. O dano me domina como uma ameaça contra a qual não posso fazer nada. Quem corre risco é o médico. Para mim, desenha-se um perigo, ou seja, um dano que, verificado, é inevitável. A alternativa ao risco, portanto, é o perigo, não a segurança. Quanto é seguro, suficientemente seguro? A questão foi formulada muitos anos atrás por Aaron Wildawsky. Não há resposta. A experiência afirma apenas que, quanto mais se aumentam as medidas de segurança, mais se incrementam os riscos. Sistemas de segurança constituídos por máquinas multiplicam, em seu interior, os riscos de controle dos controlado- 
res. A possibilidade dos cidadãos portarem armas para se defender aumenta o risco, não a segurança. A introdução de seguro obrigatório para os automóveis aumentou, de modo incontrolável, o risco de acidentes nas estradas. Segurança não é uma condição que pode ser instaurada excluindo a multiplicação, o deslocamento e a difusão dos riscos que qualquer de seus modelos produz. A política não consegue controlar os riscos que ela produz mediante a planificação de políticas de segurança.

\section{CONCEITO DE SEGURANÇA}

\section{Como podemos explicar tudo isso?}

Uma das principais caracteríticas da modernidade da sociedade moderna é o fato de que os velhos sistemas e os velhos requisitos de estabilização de expectativas não operam mais. Com o fim da estratificação, as velhas formas de segurança e garantias de estabilidade em relação ao futuro fragmentaram-se. Como não existe mais espaço para um direito natural ou para um conhecimento empírico teologicamente assegurado, o poder não pode se legitimar pela natureza do indivíduo e o fato de ser mulher ou proletário (o status) não impede o acesso ao saber. A riqueza não garante o saber que, por sua vez, não garante o poder que, por sua vez, não garante a saúde. Os sistemas sociais e os sistemas psíquicos, acoplados entre si, tornam-se instáveis a partir de si próprios, controlam-se e, quando se controlam, supreendem-se, aprendem a partir de si. Estruturas desse tipo não podem ser asseguradas pelo externo nem assegurar o externo. Elas tratam o externo apenas como o outro lado da distinção que torna possível sua própria diferenciação. Uma estrutura construída dessa maneira inicia-se sempre a partir de si, das condições colocadas por si mesma para as próprias operações. Isso siginifica que tal estrutura se auto-opera, torna-se instável e imprevisível. Para essas estruturas, segurança e estabilidade são conceitos destituídos de sentido. Conceitos que poderiam ser justificados apenas nos estreitos espaços da velha ontologia. O mesmo pode-se dizer da certeza de dispor de medidas objetivas ou estáveis que encontram lugar apenas no âmbito da velha física. Com a realização daquelas premissas e da ordem estabelecida a partir delas, as semânticas que tornaram possível a descrição daquela ordem também se modificaram. Formas de confiança, de segurança e de estabilidade evoluem da mesma forma que evolui a representação do tempo em conexão com a temporalização da complexidade que a sociedade moderna produz. Trata-se, na verdade, de uma técnica de tratamento da complexidade que a própria complexidade produz. De fato, as garantias e seguranças não são mais procuradas no passado. O passado não gera estabilidade. Agora, o problema refere-se ao futuro. $\mathrm{O}$ acesso sempre maior a um futuro que ameaça ou promete depende do observador, que pode ser 
sempre diverso. Por outro lado, o mundo superou diversos Apocalipses e, portanto, não mais se preocupa com aquilo que São Paulo chamava de "o tempo que falta", mas com o futuro que se sabe apenas que pode ser continuamente diverso. O nível mais crítico até agora atingido no transcorrer desse percurso foi a certeza que a duração do tempo que falta não mais depende da vontade de Deus, mas da capacidade que a sociedade contemporânea dispõe para controlar o potencial de autodestruição que ela mesma produz. Mas, como afirmado, a sociedade torna-se continuamente instável. Onde ela pode encontrar segurança? Onde ela pode afastar sua instabilidade? Certamente, não na ontologia, nem mesmo na natureza, seja a natureza humana seja a natureza da natureza. A erupção do futuro nos permite ver que a natureza é uma construção semântica que evolui com a evolução das semânticas pelas quais a sociedade se descreve. A natureza de Kepler ou de Copérnico não é a mesma de Newton que, por sua vez, não é a mesma de Einstein. Da mesma forma, a natureza do homem de Aristóteles não é aquela do homem de Kant e as razões da razão do Islã não são as razões da razão daquilo que se chama civilização ocidental. A erupção do futuro introduz, no palco do presente, as razões de razões diferentes. Essa mesma premissa é válida para os sistemas sociais: as razões do direito não são as mesmas da ciência que, por sua vez, não são razões da economia e estas últimas, certamente, não são as razões das pessoas quando se preocupam com a saúde. O Iluminismo da razão ocidental consumou-se com a realização de suas premissas normativas. Formaram-se os Estados modernos; inventou-se a soberania, a cidadania, os homens liberais e racionais; ativou-se um sistema universal de educação; construiu-se um sistema de imputação das ações individuais; positivou-se o direito; construíram-se organizações jurídicas econômicas e políticas. Tudo isso foi possível por causa da realização das premissas normativas iluministas. Mas, a nova ordem consumou essa normatividade, que se tornou obsoleta. Hoje constitui-se apenas como um impedimento, uma ameaça. Não consegue mais vincular o futuro e, quando tenta vinculá-lo, produz exclusão ou risco. Essa racionalidade construía o futuro olhando o passado. Dispunha somente de dois valores: ser livre ou não livre, saudável ou doente, rico ou pobre, desenvolvido ou subdesenvolvido. Segundo a forma moderna da diferenciação social, estamos vinculados justamente porque somos tratados como livres; existem novas formas de escravidão porque somos dotados de liberdade; existe mais pobreza porque existe mais riqueza; existe menos direito porque existe mais direito; somos abandonados a nós mesmos justamente porque a comunicação social é universalizada, ou melhor, somos destituídos de garantias justamente porque dispomos de garantias universais. Nessa sociedade, mais exclusão é produzida porque os sistemas sociais praticam a exclusão universal de todos no funcionamento de suas estruturas. Nessa sociedade, a única possibilidade que temos para construir vínculos com o futuro é o risco. 


\section{RISCO - PARADOXAL E CIRCULAR}

Risco é uma questão que interessa ao tempo, ou melhor, à temporalidade, vale dizer, àquela dimensão da produção de eventos que torna possível a experiência da duração apesar da mudança. Risco refere-se ao futuro, às possibilidades de construir o futuro. Mas, não só ele, também a confiança dirige-se ao futuro e o direito desempenha uma função específica nesse mesmo sentido. Podemos, seguramente, afirmar que esse é um problema urgente para a comunicação social, quando se afirma, na sociedade, uma forma de diferenciação que confere particular primado à dimensão temporal da produção de sentido. E essa é a forma de diferenciação que caracteriza a modernidade da modernidade. $\mathrm{O}$ fato que determinados sistemas sociais especializem-se na solução de problemas sociais específicos, sem as garantias oferecidas pela hierarquia ou por um centro, conduz à coexistência, no plano da temporalidade, de construções de mundos diferentes. Cada sistema constrói o mundo em seu interior. $\mathrm{E}$ isso acontece simultaneamente. Tal simultaneidade impede a observação daquilo que acontece. Impede que, de qualquer lugar, se possa controlar aquilo que acontece ou prever aquilo que acontecerá. $O$ presente é o espaço dessa simultaneidade. Contudo, é um espaço no qual não se pode indicar as dimensões, vale dizer, a duração. De outra parte, cada sistema social opera na dimensão de sua temporalidade, opera em seu presente. E é nessa dimensão que constantemente se recorda e se conecta às operações de seu ambiente. A duração, ou seja, a estabilidade na conexão dos eventos, é condição necessária para que os sistemas sociai - e também os sistemas psíquicos - não se entreguem à incontrolável e imprevisível multiplicidade dos eventos. Duração, todavia, pode ser construída somente no presente, pois, só nele, é possível escapar do futuro, tornando-o irreversivelmente atual. Entretanto, como isso pode acontecer, se o futuro é aberto, é o tempo do não-saber, vale dizer, é o tempo em que o saber do passado não significa mais nada? Em relação ao futuro, podemos apenas escolher. Como? Por meio de construções de vínculos, de vínculos com o tempo. A estabilização normativa das expectativas é um exemplo desses vínculos. Ela é uma complexa estratégia de construção de vínculos com o futuro. Produzida pelo direito, a estabilização normativa das expectativas torna possível a manutenção das próprias expectativas em caso de desilusão. Uma outra estratégia de vincular o futuro é aquela que permite que um eventual dano futuro seja imputável a uma decisão na certeza de que uma outra decisão poderia ter evitado a ocorrência do dano. Este modo de construir o futuro, este vínculo do tempo, chama-se risco. Risco, portanto, é correlato do não-saber e da necessidade de escolha. Em um outro sentido, no entanto, pode-se afirmar que é um correlato do saber. Isso se pensarmos que, quanto maior o saber, maior o não-saber; quanto maior o conhecimento, maior o não-saber das conseqüências. A descoberta de um vírus evidencia o não-saber de seu tratamento e, portanto, o risco do contágio. A descoberta do tratamento evidencia o não-saber das conseqüências. 
A descoberta de alguns efeitos evidencia o não-saber de outros. A conseqüência de tudo isso é simples. De um lado, é bastante claro que se pode evitar um risco, mas somente com a condição de se correr outro risco sem saber exatamente qual. De outro lado, se, por risco, indicamos a possibilidade de um dano futuro que uma outra escolha poderia ter evitado e, por perigo, indicamos a possibilidade de um dano futuro que uma outra escolha não poderia ter evitado, então parece evidente que, na sociedade moderna, o risco aumenta e o perigo diminui. Por essa razão, a sociedade moderna é descrita como sociedade do risco. Uma descrição que alcançou grande êxito, tornou-se moda e provocou grande alarme social. Com o alarme, difundiu-se o medo e, com o medo, a apreensão e, por consegüinte, o refúgio na moral e nos princípios éticos. O mercado se saciou de princípios e de valores, construções comunicativamente estáveis destinadas a consumidores psiquicamente frágeis. De fato, se a moral do risco é inútil, o risco da moral é alto, porque, enquanto o risco reflete a contingência do agir, a moral a elimina. E o problema mais relevante do agir é, ao invés, o tratamento da contingência. O risco é uma técnica de elaboração da contingência que, por sua vez, requer a manutenção de abertura cognitiva das estruturas dos sistemas sociais. Essa é a forma como os sistemas adaptam-se à complexidade de seu ambiente. A sociedade moderna é a sociedade do risco não no sentido ameaçador e apocalíptico que a moda difundiu. É a sociedade do risco porque somente essa sociedade criou condições para se construir futuros diferentes, para manter elevada a contingência dos eventos, vale dizer, para manter possibilidades sempre abertas quando, em razão de uma decisão, verificou-se um eventual dano que se queria ter evitado e que uma outra decisão poderia ter evitado.

Esse risco está ambiguamente entre saber e não-saber. Não há risco quando não se sabe que pode ocorrer um dano futuro em conseqüência da decisão. Também não há risco se a superação do dano é certa. O saber constitui uma parte da duplicidade do risco. A outra parte é formada pelo não-saber do futuro que se tornará presente após a escolha decisória. Em relação a esse não-saber, qualquer outro saber não diz absolutamente nada. O paradoxo do risco permanece. A estatística pode absorver incerteza. Pode dar esperança eliminando a contingência, mas, sobre o risco do evento, não pode afirmar nada. Todo o saber do risco refere-se ao passado. O fato de que $95 \%$ das cirurgias no intestino sejam bem-sucedidas, não diz nada sobre minha cirurgia. Não garante se minha cirurgia estará entre os $95 \%$ ou os $5 \%$. E, quando a realidade dos eventos não corresponde à estatística, muda-se essa última naturalmente. A construção paradoxal do risco nasce do fato de que o risco é uma construção da comunicação social que não apenas o constrói, mas, quanto mais o trata, mais o aumenta. Esse efeito distorce a percepção do risco, concentra a atenção sobre certos riscos e a afasta de outros. Isso comporta graves conseqüências na construção do futuro, trabalhado de maneira diferente em cada sistema social. A amplificação 
do risco se verifica pois o risco é tratado como tema da comunicação e não, como se diz, pela sua presumida objetividade. É por isso que o aumento da informação não diminui o risco. Basta considerar como realmente são desinformados os serviços de informação. Quanto são estúpidas as decisões tomadas em virtude de suas informações. Veja-se, por exemplo, as discussões sobre o risco da AIDS nos anos 1980 e 1990. Era o apocalípse. Enquanto isso, todos os dias, o número de mortos por acidentes automobílisticos nas estradas do mundo era infinitamente mais alto. São dois exemplos que provam como amplificação e pânico não diminuem o risco. Podem, ao contrário, aumentar o perigo, vale dizer, a impossibilidade de evitar eventual dano futuro resultado das decisões de outros. Nos sistemas sociais, isso acontece como resultado das operações efetuadas no ambiente de qualquer um desses sistemas, com base na percepção e na elaboração do risco que qualquer desses sistemas realiza. O mesmo acontece com cada indivíduo.

\section{ESTRUTURAS DE DECISÃO}

A essa altura, já deve estar claro a estrutura paradoxal e circular do risco. Sobre ela pode-se apenas tentar racionalizar o medo. Aumento do risco significa, paradoxalmente, incremento das possibilidades de evitar o risco à medida que se disponha correr outros riscos. Dissemos que, na sociedade moderna, cada sistema social constrói o mundo no seu interior. Trata-se de uma prestação arriscada porque acontece, simultaneamente, a outras prestações arriscadas ocultas entre si, uma vez que um sistema não controla a operação do outro. Nessas condições, a racionalidade clássica tem pouca valia. O mesmo se diga das morais, dos princípios e das éticas de responsabilidade. Além de inúteis para o nosso problema, todos esses ingredientes são perigosos. Nenhum deles pode indicar o que fazer na situação concreta. Fronteiras podem ser fechadas para evitar imigração de massa; mas, desse modo, fomenta-se a imigração clandestina e as organizações criminais que a controlam são reforçadas. Pode-se impor a defesa dos chamados valores ocidentais; porém, se radicaliza o Islã. A democracia pode ser defendida com a força e produzir a guerra civil. Pode-se afirmar tolerância zero, entupir as prisões de indivíduos e construir, assim, milhões de candidatos reais a futuros cárceres penais. Poderíamos continuar com os exemplos. Não existe uma competência social para o tratamento do risco. Não existe uma racionalidade universal que possa evitar o risco e desvinculá-lo como vínculo temporal da produção dos eventos. Todos os sistemas sociais - e também os sistemas psíquicos - se expõem a operações arriscadas. Enquanto construção da comunicação e particularmente ambíguo, o paradoxo a que chamamos risco não pode ser enfrentado por meio de mecanismos fundados na causalidade. São essas intervenções que impedem a existência da própria causalidade. Por esse motivo, as políticas de segurança 
não funcionam. Agora fica claro porque as campanhas de destruição das plantações de coca na Bolívia não funcionaram. Do mesmo modo, pesquisas empíricas por nós realizadas demonstraram que as chamadas camapanhas de prevenção do risco funcionam com destinatários que nunca teriam corrido o risco que se quer evitar. Nos outros destinatários, funciona a ilusão do controle, reforçada pela comunicação ativada pelas campanhas de prevenção. A racionalidade de tratamento do risco afasta a obtusa e rígida forma da causalidade, o vazio dos princípios, a insuficiência do cálculo racional e a abstração da otimização das escolhas. Há alguns anos, uma grande companhia da seguros me convidou para realizar uma conferência sobre risco. O evento foi realizado para premiar um certo número de assegurados que, nos últimos vinte cinco anos, não sofreram ou provocaram nenhum acidente. Enquanto falava, não conseguia não pensar: "Coitados! Pagaram inutilmente por vinte e cinco anos." Por outro lado, a alternativa de não pagar inutilmente o seguro seria ter sofrido um acidente. Uma alternativa que não pode ser festejada.

Com esse exemplo, posso refletir brevemente sobre uma característica complementar do risco. O risco pode ser monetarizado. Isso significa que qualquer tipo de risco pode ser transformado em risco econômico. Trata-se de uma técnica largamente praticada e difundida que, sem dúvida, pode provocar um grande incremento do risco. Esse incremento é produzido em dois sentidos completamente diversos. Aquele que está assegurado contra o risco é levado a praticar um comportamento arriscado, justamente porque, na hipótese de verificação do risco, sente-se seguro. Esse comportamente, entretanto, é visto como perigo para os outros. O médigo assegurado está menos preocupado com eventuais conseqüências negativas de seus diagnósticos do que um médico que não tenha seguro. O paciente vive o risco do erro como um perigo do qual não pode fugir e contra o qual não pode agir até a produção efetiva do dano. Antes disso, não pode fazer nada para evitá-lo. Ressalte-se, entretanto, que o risco da monetarização do risco se incrementa também em um outro sentido. Depois da catástrofe de New Orleans, o governo dos Estados Unidos transferiu aos entes privados instrumentos e estruturas organizativas para a proteção civil. Na próxima catástrofe, os socorros deverão ser prestados pelas empresas privadas. Em outras palavras: deve-se pagar para ser socorrido! Quem não tem condições de pagar o helicóptero de salvamento, tristemente se afogará com os móveis da casa onde vivia. O argumento é: maior eficiência! A realidade é: maior exclusão! Ora, uma catástrofe é um perigo. O conhecimento e a tecnologia tendem a transformá-la em risco. As conseqüências danosas podem ser em grande parte evitadas. A economia reintroduz o perigo para alguns e o risco econômico para outros. Uma técnica bárbara que produz exclusão por meio de inclusão. Todos podem concordar com a possibilidade de evitar o risco. Todos têm direito. Mas, é desse modo que se verifica que, no mesmo país, 46 milhões de pessoas estão excluídas da assistência médica e sanitária. De fato, o risco não pode ser jurisdicizado. Diante do risco, o direito evidencia 
seus defeitos de construção. O problema não pode ser resolvido com mais ou menos direitos. A questão interessa à técnica jurídica, que pode intervir antes da ação, impedindo que ela aconteça e, por conseguinte, antes que se saiba se eventual dano futuro teria acontecido, ou pode intervir depois de ocorrido o evento danoso.

As conseqüências danosas são canalizadas para o plano da economia ou do próprio direito. De outra parte, as pretensões de tratamento do risco são sempre mais persistentes porque o saber sobre o risco, isto é, o saber sobre a possibilidade de evitá-lo, é sempre mais amplo. Em alguns momentos, estas pretensões são direcionadas prevalentemente ao sistema político, representado como sistema central e compelido a tomar decisões vinculantes. Mas, o sistema político não pode considerar todas as conseqüencias de suas decisões. Primeiramente, porque está exposto ao risco da perda de consenso, principal recurso de legitamação de suas decisões. E, ainda, porque a estrutura dos sistemas sociais, como afirmamos, exclui a centralidade e a verticalidade de um sistema em relação aos outros. As decisões da política produzem conseqüências que podem ser arriscadas para os demais sistemas sociais. A construção do mundo realizada pela política é, na realidade, uma construção política do mundo. Na economia, como no direito ou no sistema da saúde, acontece aquilo que acontece. Uma intervenção posterior da política para o tratamento das conseqüências dos decisões anteriores produzirá outras conseqüências cujo grau de risco será apenas outro. Se afima que a política é um sistema de distribuição de recursos. A política, na verdade, distribui apenas riscos. Isso ocorre porque o sistema político opera orientado pelo controle dos riscos da política e está continuamente exposto ao risco das conseqüências de suas decisões.

Na sociedade contemporânea, existem condições estruturais que permitem ver que o futuro depende cada vez mais das decisões tomadas no presente. Isso significa que, simultaneamete à produção de risco, são criadas possibilidades para seu tratamento, isto é, são criadas possibilidades para evitar riscos que devem ser evitados. Em outras palavras: dispomos de possibilidades que nenhuma outra sociedade dispôs. Todavia, somente estruturas altamente complexas conseguem desenvolver técnicas de tratamento do risco que mantenham abertas alternativas da ação e são capazes de rever suas próprias decisões. Estruturas desse tipo são consolidadas no interior dos sistemas sociais, caracterizados por orientação cognitiva. São sistemas sociais capazes de aprender consigo próprios, usando como informações os resultados de elaboração da complexidade que eles próprios produzem. São sistemas dotados de grande capacidade evolutiva, vale dizer, de grande capacidade de adaptação ao ambiente.

Se o futuro depende cada vez mais das decisões, o leque de possibilidades de construir o futuro depende da complexidade que essas máquinas decisionais são capazes de produzir no presente. Simultaneidade do acon- 
tecer, não-transparência, fechamento dos sistemas sociais, inclusão universal de todos em seu interior são os requisitos da complexidade tipicamente moderna da sociedade. São esses requisitos que possibilitam o tratamento dos perigos herdados do passado e a eliminação das antigas barreiras da ontologia e da estratificação geradoras desses perigos. Permitem, ainda, vincular o futuro por meio do risco, isto é, observar as possíveis soluções para problemas antigos na certeza de que essas soluções geram novos problemas, mesmo se não sabemos quais. Em outras palavras: esta sociedade pode reduzir os perigos, vale dizer, o inevitável, as barreiras, os impedimentos. Pode reduzir a extensão daquilo que outras sociedades atribuíam à natureza pelo simples motivo que, dessa forma, podiam atribuir objetividade às suas bárbaras distinções. Essa sociedade dispõe de potencial porque esses requisitos estruturais da produção e do controle da complexidade tornaram-se operativos. Essa sociedade, por exemplo, tem um alto potencial para a democracia. Mas, também para a autodestruição. Até agora tem prevalecido a tendência em relação ao segundo mais do que à realização explosiva do primeiro.

\section{CONCLUSÕES}

O sistema da saúde foi, até agora, um sistema especializado no tratamento das doenças. A própria medicina se ocupava quase exclusivamente do tratamento das moléstias. Havia muitas enfermidades e uma única saúde, afirmava Luhmann. O saber médico intervinha após ocorrido o risco da doença. A medicina curava ou não curava, enquanto seu conhecimento se especializava em relação ao saber ou ao não-saber da doença. Sistemas de seguros monetarizavam o risco da doença. A universalização dos sistemas de seguros tendia a reduzir os perigos das doenças e a incremetar os riscos. Os riscos da doença eram, assim, transferidos diretamente ao sistema político, à economia e ao direito. A saúde era uma condição que existia ou não existia. No âmbito da doença, formavam-se duas grandes distinções: doenças de contágio (de infecção), largamente difundidas nos países em que as codições ambientais, de trabalho, de vida e de sobrevivência tornavam-se incontroláveis e doenças da civilização, mais difundidas nos países em que as condições de vida eram melhores e nos quais os sistemas sociais operavam com base na inclusão generalizada de todos. A diferença na tipologia das doenças correspondia à diferença usada para representar o mundo, distinguindo entre mundo desenvolvido e mundo em vias de desenvolvimento, conforme se afirmava em uma perversa sofisticação semântica.

Atualmente, a medicina introduziu outras distinções. De um lado, a genética permite saber se uma vida futura se desenvolverá com risco de doenças, podendo, portanto, ser ou não considerada geneticemante saudável ou, ainda, saber se uma vida futura já carrega o perigo ou mesmo a certeza da doença. A outra distinção que conhecemos é aquela entre doenças curáveis e incuráveis. 
Essas novas condições da medicina produziram grandes transformações nos modos de gestão dos sistemas de saúde. Também aqui o futuro depende sempre mais das decisões tomadas no presente. Quais decisões? A política, a qual, antes de qualquer outra, reorienta as pretensões e as exigências dos indivíduos e transfere os riscos para a economia e para o direito. O último socorro vem da religião, que transfere o risco à moral. Universalizou-se um direito à saúde, isto é, se transformou um problema real em um paradoxo que oculta o problema. $\mathrm{O}$ direito à saúde tem, na realidade, a função de generalizar a doença como risco, isto é, saber que outra decisão poderia tê-lo evitado. Quando a doença é um perigo, tem a função de confiar cada indivíduo a sua sorte. Mas, o que posso fazer frente aos buracos na camada de ozônio? De um lado, o direito fixa valores-limites que dependem da tolerância econômica frente aos comportamentos desviantes. Esses valores-limites referem-se ao passado e não ao futuro e não dizem nada a respeito daquilo que pode acontecer no futuro caso se viva às margens do valor-limite. Se, no futuro, aquilo que acontecer ocorrer dentro do limite do valor-limite, o que mudará é o próprio valor-limite. De outro lado, o direito pode impor controles, isto é, pode tratar os saudáveis como se fossem doentes. Mas, assim como não é possível adotar medidas de eugenia, porque já conhecemos seus efeitos trágicos, também não é possível controlar os micróbios barrando-os nas alfândegas de fronteira. Os controles têm uma função política, não médica. Exceção, claro, nos casos em que se sabe que uma intervenção preventiva evitará, com certeza, o surgimento de uma doença. E mais: tratar os saudáveis como doentes é um problema enfrentado mais pela economia do que pelo direito. De fato, os problemas mais agudos da doença tornaram-se quase exclusivamente problemas econômicos. Desde que, ao final dos anos oitenta, o Banco Mundial divulgou seus perversos estudos sobre custos da doença e começou a oferecer seus conselhos ameaçadores sobre os modos para enfrentar estes custos, os riscos da doença tornaram-se, desde então, riscos econômicos. A economia universalizou estes riscos, periferizou seus custos e realizou, ainda que por meio da doença, a inclusão dos excluídos do sistema da economia mundial. Os custos humanos foram transferidos para aquilo que uma semântica perversa continua a chamar de terceiro mundo. Nos países deste mundo, aproximadamente $75 \%$ (setenta e cinco por cento) da assistência médica foi privatizada. A doença é um perigo contra o qual os indivíduos excluídos não podem fazer nada. Esses indivíduos naturalmente são titulares de um direito à saúde. Como se diz, são livres. Livres para permanecer no abismo a que se referia Pinter. Resta o pronto-socorro da moral, dos princípios, da compaixão. Todavia, a moral tem uma particular aversão ao risco, assim como a religião. Elas aconselham a penitência pelas decisões tomadas. Um conselho que estendem à política e aos indivíduos.

Luhmann disse uma vez: a diferença entre a religião e as nossas idéias sobre o risco é que a religião está interessada em aumentar as culpas e as penitências e nossas idéias sobre o risco buscam diminuí-las. Visam, assim, à tomada de decisões sobre as quais, no futuro, não seja necessário concluir que outras decisões poderiam ter evitado o dano verificado. 